\title{
A high-pressure atomic force microscope for imaging in supercritical carbon dioxide
}

\author{
A.S. Lea, ${ }^{1}$ S.R. Higgins,${ }^{2}$ K.G. Knauss,${ }^{3}$ and K.M. Rosso ${ }^{4}$ \\ ${ }^{1}$ Environmental Molecular Sciences Laboratory, Pacific Northwest National Laboratory, Richland, WA 99352, USA \\ ${ }^{2}$ Department of Chemistry, Wright State University, Dayton, Ohio 45435, USA \\ ${ }^{3}$ Division of Earth Sciences, Lawrence Berkeley National Laboratory, Berkeley, California 94444, USA; (KGK's work \\ work was supported by the U.S. Department of Energy and LBNL under Contract No. DE-AC02-05CH11231.) \\ ${ }^{4}$ Chemical and Materials Sciences Division, Pacific Northwest National Laboratory, Richland, Washington 99352, USA
}

\begin{abstract}
A high-pressure atomic force microscope (AFM) that enables in situ, atomic scale measurements of topography of solid surfaces in contact with supercritical $\mathrm{CO}_{2}\left(\mathrm{scCO}_{2}\right)$ fluids has been developed. This apparatus overcomes the pressure limitations of the hydrothermal AFM and is designed to handle pressures up to $100 \mathrm{~atm}$ at temperatures up to

$\sim 350$ K. A standard optically-based cantilever deflection detection system was chosen. When imaging in compressible supercritical fluids such as $\mathrm{scCO}_{2}$, precise control of pressure and temperature in the fluid cell is the primary technical chal- lenge. Noise levels and imaging resolution depend on minimization of fluid density fluctuations that change the fluid refractive index and hence the laser path. We demonstrate with our apparatus in situ atomic scale imaging of a calcite $\left(\mathrm{CaCO}_{3}\right)$ mineral surface in $\mathrm{scCO}_{2}$; both single, monatomic steps and dynamic processes occurring on the (1014) surface are presented. This new AFM provides unprecedented in situ access to interfacial phenomena at solid-fluid interfaces under pressure.
\end{abstract}

\section{INTRODUCTION}

Atomic force microscopy has been an invaluable tool in fields such as geochemistry for garnering information on fundamental reaction rates of minerals in aqueous solutions under controlled conditions. For example, numerous studies on the growth and dissolution of calcite $\left(\mathrm{CaCO}_{3}\right)$ with or without impurities have been conducted in aqueous media. ${ }^{1-10}$ Similar studies have provided detailed information for quartz, ${ }^{11,12}$ periclase, ${ }^{13}$ and dolomite. ${ }^{14}$ The ability to image in situ in real-time has always been desirable for its advantage of eliminating the need to alter experimental conditions between images. For a number of mineral systems (e.g., oxides and silicates), rates of dissolution and growth reactions at room temperature are too slow to be measured by conventional in situ atomic force microscope (AFM) instrumentation. In 1998, Higgins et al. developed the hydrothermal $\mathrm{AFM}^{15}$ so as to gain access to mineral growth and dissolution rates in aqueous media at elevated temperatures and concomitant mildly increased pressures. That development allowed researchers to measure otherwise slow reaction rates more efficiently, for minerals such as magnesite, ${ }^{16-18}$ barite, ${ }^{19}$ plagioclase feldspars,${ }^{20}$ and phyllosilicates. ${ }^{21}$

A need now is present to be able to study mineral-fluid interfaces at high pressure with concomitant mildly elevated temperature. For example, geologic sequestration of $\mathrm{CO}_{2}$ is an emerging enterprise for reducing greenhouse gas emissions. The $\mathrm{CO}_{2}$ will be injected and stored in porous host rock at depths (approximately $>800 \mathrm{~m}$ ) where lithostatic pressure will maintain it in a supercritical fluid state $\left(\mathrm{scCO}_{2}\right)$. Knowledge of mineral-fluid chemical transformation rates at geo- logically relevant combinations of pressures and temperatures (i.e., consistent with the geothermal temperature gradient) is anticipated to be an important aspect of predicting the stability of subsurface $\mathrm{CO}_{2}$ reservoirs. In contrast to the AFM studies in aqueous media mentioned above, access to conditions greater than the critical point of $\mathrm{CO}_{2}(>72.8 \mathrm{~atm}$ and $>304 \mathrm{~K})$ are needed. Furthermore, many of the mechanisms of mineral transformation reactions where water availability is low and the dominant fluid is the gaslike nonpolarizable solvent $\mathrm{scCO}_{2}$ have so far remained relatively unstudied. There are therefore new needs for and unique challenges in obtaining kinetic and thermodynamic data of the kind that in situ AFM can provide for mineral transformation reactions in this fluid.

There have been a few studies examining the reaction of minerals in $\mathrm{scCO}_{2}$ using $\mathrm{AFM},{ }^{22,23}$ but because of the limited operating pressure range, these investigations have been limited to ex situ analyses. That is, the mineral is examined under ambient conditions before and after, but not during the reaction. While one can get an approximate measure of the bulk rate of dissolution or growth processes that occur on the surface by monitoring changes in topography (preferably in the same location) before and after the reaction, knowing only the endpoints provides little insight to atomic scale reactions that do occur. Ex situ analyses also force the experimenter to impose a change in experimental conditions to collect an image, such as releasing pressure and/or temperature to ambient conditions, a step that can introduce artifacts that obscure the desired information. In situ analyses enable one to monitor real-time step motion and surface kinetics, enabling the measurement of step-specific growth/dissolution processes, which yields information on rates of formation of kinks and 
double-kink sites, for example, as well as step-specific reaction activation energies. Without the ability to operate at pressures and temperatures exceeding the critical point of $\mathrm{CO}_{2}$, this detailed microscopic information is unattainable.

Present-day commercial AFM systems have the ability to image surfaces at temperatures up to about $500 \mathrm{~K}$, but are extremely limited in their ability to operate in positive pressure regimes; typically, only a few atmospheres. Here we report the development of a high-pressure $\mathrm{scCO}_{2} \mathrm{AFM}$ that enables in situ analysis of solid surfaces at pressures up to $100 \mathrm{~atm}$ at temperatures up to $\sim 350 \mathrm{~K}$. This instrument is based on the hydrothermal $\mathrm{AFM}^{15}$ and incorporates a number of similar features. The hydrothermal AFM can operate at pressures up to $\sim 10 \mathrm{~atm}$, though a second generation hydrothermal AFM developed by Jordan and Astilleros ${ }^{24}$ has the capacity to operate at pressures up to $50 \mathrm{~atm}$. Both of these instruments, however, still operate below the $\mathrm{CO}_{2}$ critical point pressure of $72.8 \mathrm{~atm}$.

\section{DESIGN CONSIDERATIONS}

Aside from the obvious need for increased AFM wall thickness and larger gauge hardware to accommodate the increased operating pressures, consideration in our case has to be given to the contribution of $\mathrm{scCO}_{2}$ compressibility to the noise in the optical lever detection system. Small temperature and pressure variations can lead to large changes in fluid density (depending on the specific combination of desired operating temperature and pressure), which in turn impacts the refractive index of the medium. In our fluid cell design, the laser light reflected from the back of the cantilever is refracted at the $\mathrm{scCO}_{2}$-sapphire window interface, the extent of which depends on the time-dependent fluid density. One can calculate the pressure of the $\mathrm{scCO}_{2}$ at any given temperature and density condition by solving for the partial derivative of the residual dimensionless Helmholtz energy with respect to density for the equation of state given by Span and Wagner ${ }^{25}$ (see Tables 3 and 32 therein):

$$
p(\delta, \tau) / \rho R T=1+\delta \phi_{\delta}^{r},
$$

where $p$ is the pressure, $T$ is the temperature, $\rho$ is the density, $\delta$ is the reduced density with respect to the critical density of $\mathrm{scCO}_{2}, \tau$ is the inverse reduced temperature with respect to the critical temperature of $\mathrm{scCO}_{2}, R$ is the gas constant, and $\phi_{\delta}^{\mathrm{r}}$ is the partial derivative of the residual dimensionless Helmholtz energy with respect to density. From these calculations, one can extract density as a function of pressure at any given temperature and the corresponding refractive index $(\eta)$, which is given by the classic Lorentz-Lorenz equation:

$$
\eta^{2}=(2 r \rho+1) /(1-r \rho),
$$

where $r$ is the specific refraction at a wavelength of $670 \mathrm{~nm}$ and is given by $1.51 \times 10^{-4} \mathrm{~m}^{3} \mathrm{~kg}^{-1} .{ }^{26}$ The pressure dependent density and refractive index variations for a number of temperatures ranging from 310 to $350 \mathrm{~K}$ are shown in Fig. 1. A similar graph (not shown) depicting the density and index of refraction variations as a function temperature for a

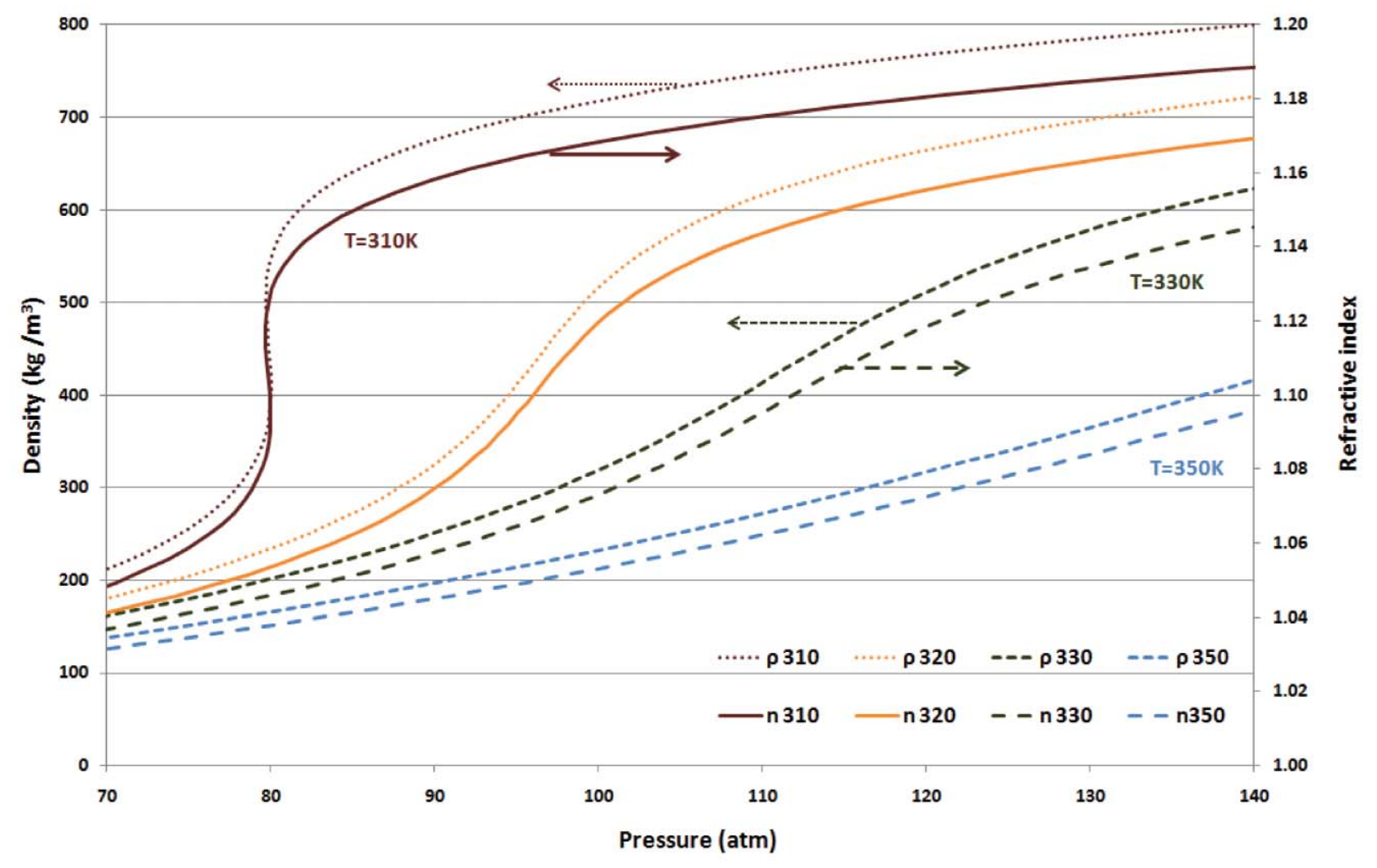

FIG. 1. (Color online) Density and refractive index of supercritical $\mathrm{CO}_{2}$ as a function of pressure up to 140 atm for temperature isotherms $310-350 \mathrm{~K}$. Large changes in slope at specific temperature and pressure conditions reflect the potential for considerable noise in the optical detection system induced by temperature and pressure fluctuations. 
number of pressure isobars shows similar dependence. Not surprisingly, large variations in density and refractive index are observed at temperatures and pressures near the critical point and so operating the instrument under these conditions would impart the largest noise susceptibility to the optical lever detection system. Still, there are other conditions under which even small changes in temperature and pressure can lead to dramatic changes in density. These are represented by the large slope changes on the isotherms shown in Fig. 1. We had initially chosen a target temperature and pressure condition that was easily attainable with our apparatus and had a density that was considered somewhat insensitive to temperature and pressure fluctuations (shallow slope on the isotherms). Under these conditions, we wanted to calculate the impact of the temperature induced density changes on the noise in the detection system to establish whether such an instrument is feasible. At $340 \mathrm{~K}$ and $80 \mathrm{~atm}$, one can calculate the expected temperature induced contribution to the noise using a sapphire refractive index of 1.764944 calculated from the Sellmeier dispersion equation, ${ }^{27}$ a $50 \mu \mathrm{m}$ long cantilever inclined at $12^{\circ}$, Eqs. (1) and (2) and Snell's law:

$$
\eta_{1} \sin \theta_{1}=\eta_{2} \sin \theta_{2}
$$

In this case, a $\Delta T$ of $0.1 \mathrm{~K}$ translates to a $\Delta \eta$ of 0.000037 and is comparable to a $4 \AA$ deflection. We can deduce from this calculation that a temperature stability of $<0.1 \mathrm{~K}$ over a period of a few seconds is necessary if we wish to see atomic scale steps on mineral surfaces. This necessitates tight temperature control to mitigate substantial temperature gradients and dictates that we place the entire AFM head in an oven temperature controllable to $\pm 0.1 \mathrm{~K}$. Pressure variations of $\sim 0.02 \mathrm{~atm}$ at this temperature and pressure also induce noise comparable to a $4 \AA$ deflection and so it is critical to utilize a low-noise syringe pump in our fluid delivery system.

\section{DESIGN}

A Nanoscope ${ }^{\mathrm{TM}}$ IIIa Multimode AFM system (Bruker AXS, Santa Barbara, CA) was utilized to operate the $\mathrm{scCO}_{2}$ $\mathrm{AFM}$ and, as similar to the HAFM, ${ }^{15}$ we have tapped into the piezoelectric scanner, the stepper motor and the optical head control signals from the Multimode AFM base to produce a functional apparatus. This new apparatus is designed to operate in contact mode imaging only. The Multimode AFM optical head, which contains the laser diode and the position-sensitive photodiode detector, was utilized to monitor cantilever deflection in the fluid cell. This optical head was modified to accommodate the $1.25 \mathrm{in}$. diameter fluid cell by removing the tip-holder clamping fork, thinning the back wall, and fitting with a new base plate in order for kinematic integration with the high-pressure AFM body. In this configuration, the head is positioned such that the light enters the fluid cell normal to the sapphire window, reflects off the cantilever back toward the sapphire window, where it is refracted into the cylindrical lens in the optical head which focuses the beam onto the position-sensitive photodiode detector.

The high-pressure AFM body is depicted schematically in Figs. 2 and 3. Fig. 2 shows the entire apparatus, whereas Fig. 3 depicts a close-up view of the fluid cell portion of the

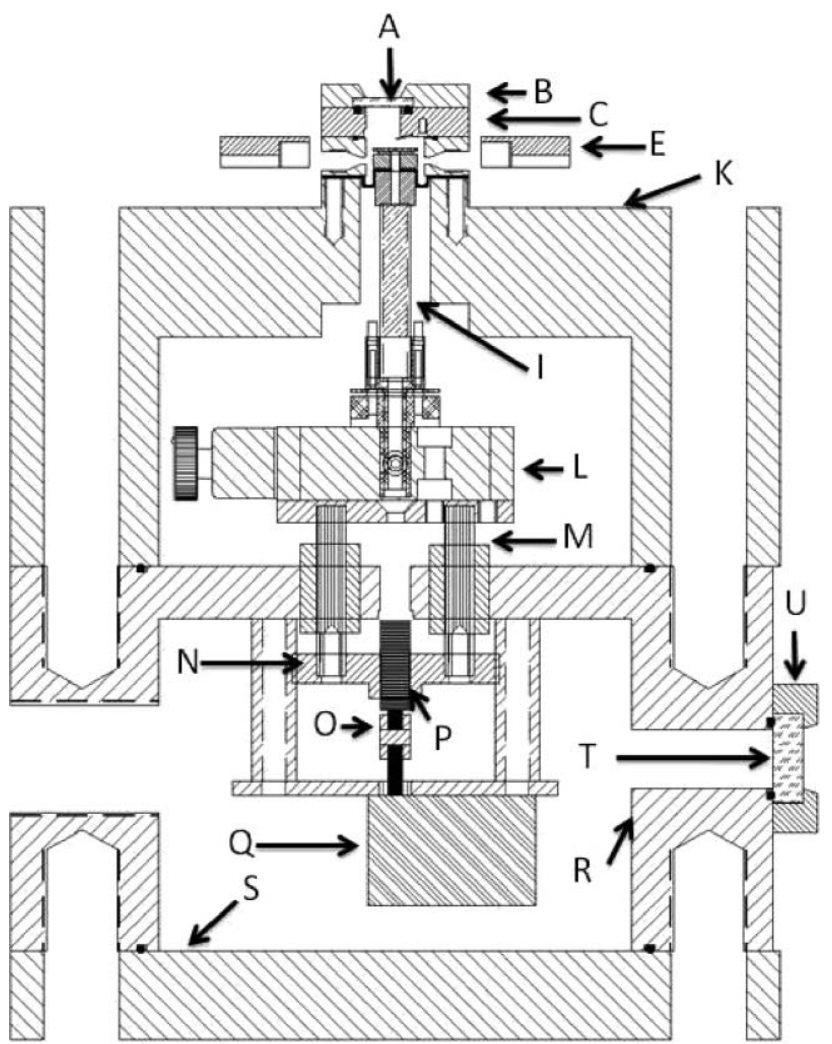

FIG. 2. Schematic of the high-pressure AFM head showing sapphire window (A), window cover (B), fluid cell (C), optical head base plate (E), scanner housing $(\mathrm{K})$, translational components $(\mathrm{I}, \mathrm{L}-\mathrm{Q})$, stepper motor housing $(\mathrm{R}, \mathrm{S})$, stepper motor housing window $(\mathrm{T})$, and stepper motor housing window cover (U).

apparatus. For clarity, we use a continuous lettering sequence in which components depicted in both figures are repeated by the same letter. It is comprised primarily of the stainless steel stepper motor and piezoelectric scanner housings and a titanium fluid cell. Titanium was chosen for the fluid cell because of its well-known resistance to corrosion when properly passivated. The sample is mounted on a mounting disk $(\mathrm{G})$ inside a fluid cell $(\mathrm{C}, \mathrm{F})$ comprised of commercially pure titanium components, thermally oxidized for passivation. ${ }^{28,29}$ Specifically, we use Grade 2 titanium, which is the most nearly pure

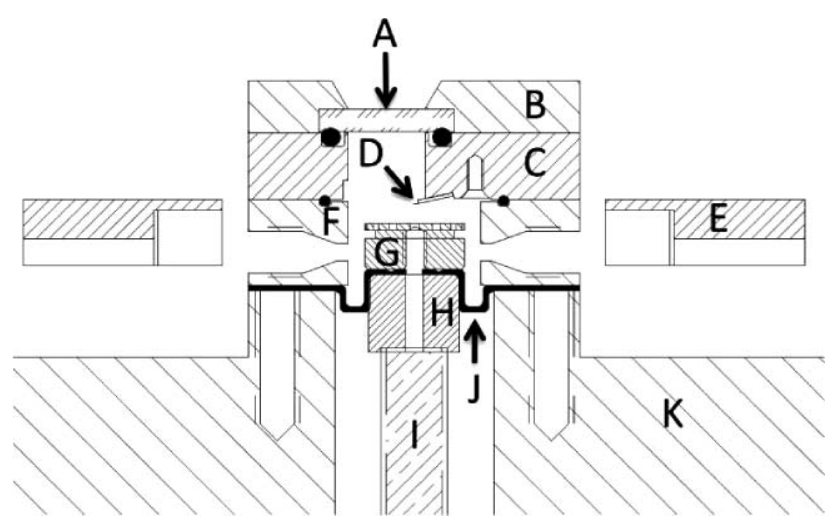

FIG. 3. Schematic of the fluid cell portion of the high-pressure AFM head. The fluid cell region consists of a sapphire window (A), window cover (B), titanium cantilever holder (C), cantilever (D), optical head base plate (E), titanium fluid cell $(\mathrm{F})$, the titanium sample disk $(\mathrm{G}), \operatorname{Macor}^{\mathrm{TM}}$ spacer $(\mathrm{H})$, piezoelectric scanner (I), Kalrez ${ }^{\circledR}$ membrane $(J)$, and scanner housing $(\mathrm{K})$. 
and has the lowest Fe content of the commercially pure grades that are readily available. The contents of the fluid cell (Fig. 3) are separated from the translational components in the scanner housing $(\mathrm{K})$ and the stepper motor housing $(\mathrm{R}, \mathrm{S})$ using a custom molded Kalrez ${ }^{\circledR} 7075$ membrane (DuPont) (J) that permits unfettered raster motion of the piezoelectric scanner (I). This isolation precludes the $\mathrm{scCO}_{2}$ from having negative impacts on the operation of the translational components of the system. The top of the fluid cell (B) is fitted with a sapphire window (A) for chemical inertness and to permit laser light in and out of the cell to interrogate cantilever deflection due to surface topography of the sample rastering below the AFM tip. The fluid cell is machined with a fluid inlet port, a fluid outlet port, and a thermocouple port that enables temperature monitoring of the cell contents. The cantilever (D), angled at $12^{\circ}$ from horizontal, is held in place using a titanium spring clip and retaining screw.

The sample mounting disk is mechanically connected to a Macor ${ }^{\mathrm{TM}}$ spacer $(\mathrm{H})$ attached to the top of a PZT-5A piezoelectric tube scanner (I) (EBL Products) with a horizontal scan range of $\sim 45 \mu \mathrm{m}$ and a vertical range of $\sim 2.5 \mu \mathrm{m}$. The piezoelectric scanner, with a Curie temperature of $623 \mathrm{~K}$, is mounted on a motorized translational stage (New Focus 8051) (L) with a range of motion of approximately $\pm 3 \mathrm{~mm}$. The computer controlled translational stage is considered an important, but nonessential, component of the system as it allows for coarse lateral positioning of the sample without the need for system depressurization and repressurization. The translational stage is affixed via linear bearings (M) to an 80 thread per inch, leadscrew $(\mathrm{P})$ driven advance plate $(\mathrm{N})$ that, through a helical coupler $(\mathrm{O})$, is connected to the coarse positioning stepper motor (Q). Remote control of these translational components is possible through high-pressure electrical feedthroughs (not shown) rated to 408 atm (Conax Technologies). Observation of the stepper motor housing interior is possible through incorporation of a sapphire window (T) and window cover (U) into the housing.

While the upper pressure limit of $100 \mathrm{~atm}$ is determined from the design and construction of the AFM head, the temperature limit is ill-defined and is constrained primarily by operational performance of the laser diode. At temperatures much above $350 \mathrm{~K}$, both the power output and lifetime of the laser diode diminish significantly and so we have not attempted to operate the instrument at temperatures above this soft limit.

\section{FLUID DELIVERY SYSTEM}

While the high-pressure AFM head and kinematically integrated optical head are operated inside a $\pm 0.1 \mathrm{~K}$ regulated oven (Thelco 6545), the fluid delivery system remains outside the oven at ambient temperature. Pressurized liquid carbon dioxide enters the oven through a $4 \mathrm{ft}$ coil of 0.030 in. I.D. PEEK tubing. At typical flow rates of $500 \mu \mathrm{l} \mathrm{min}-1$ or less, the carbon dioxide reaches the fluid cell at temperatures exceeding the critical temperature of $\mathrm{CO}_{2}$ and is stable (i.e., $<0.1 \mathrm{~K}$ variation) according to thermocouple output readings. A schematic of the fluid delivery system is shown in Fig. 4. In our setup, a bladder accumulator (Young Engineering) is connected to both a siphon $\mathrm{CO}_{2}$ tank with $99.999 \%$ purity (Matheson) and a nitrogen tank (99.9995\%, A-L Compressed Gases) to sustain pressures above the critical pressure of $\mathrm{CO}_{2}$ (72.8 atm). This setup allows for pressurization of system with the $\mathrm{CO}_{2}$ confined to the fluid cell and the nitrogen confined to the space below the Kalrez ${ }^{\circledR}$ membrane, consisting of the scanner and stepper motor housings. In this setup, the HiP valves (High Pressure Equipment) and tubing on the $\mathrm{CO}_{2}$ leg are made from Hastelloy HC276 for chemical inertness, whereas those on the nitrogen leg are made from 316 stainless steel. It is important to pressurize the system slowly

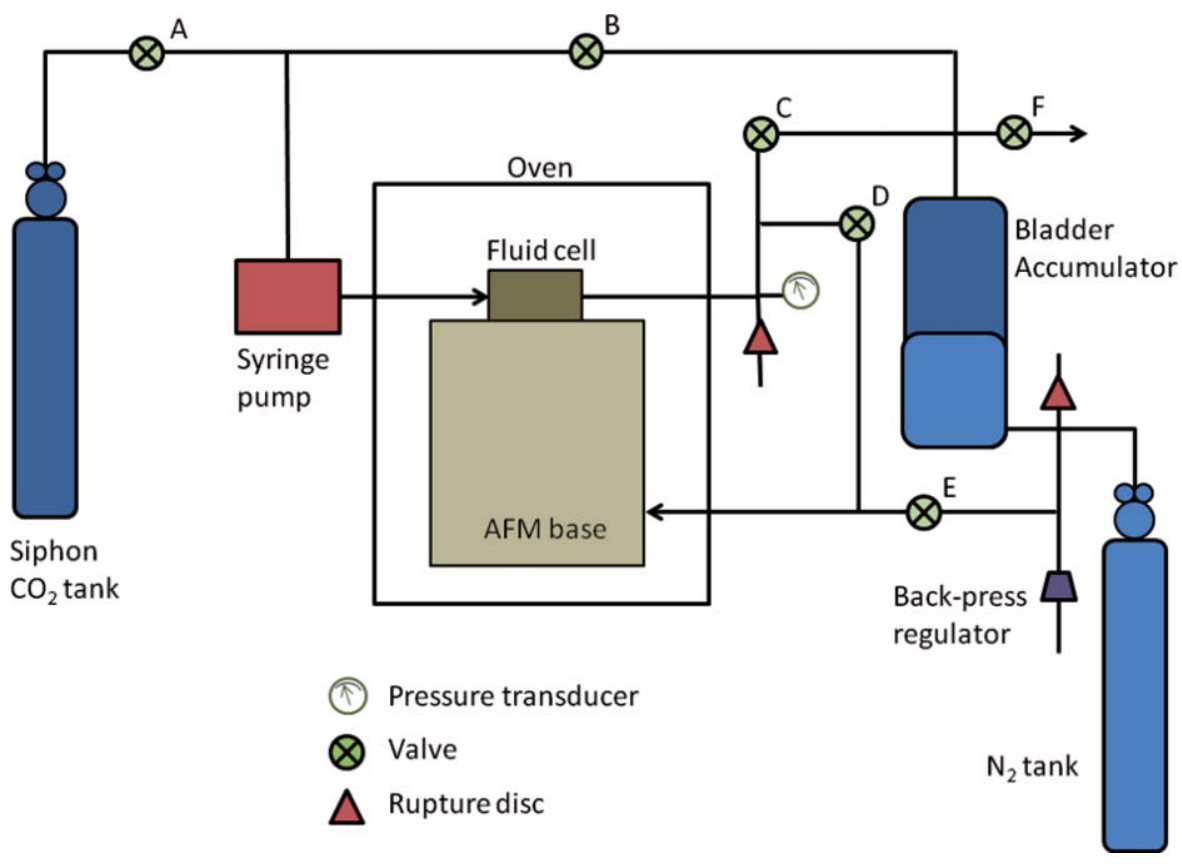

FIG. 4. (Color online) Schematic of the fluid delivery system. Valves are labeled A-F. 


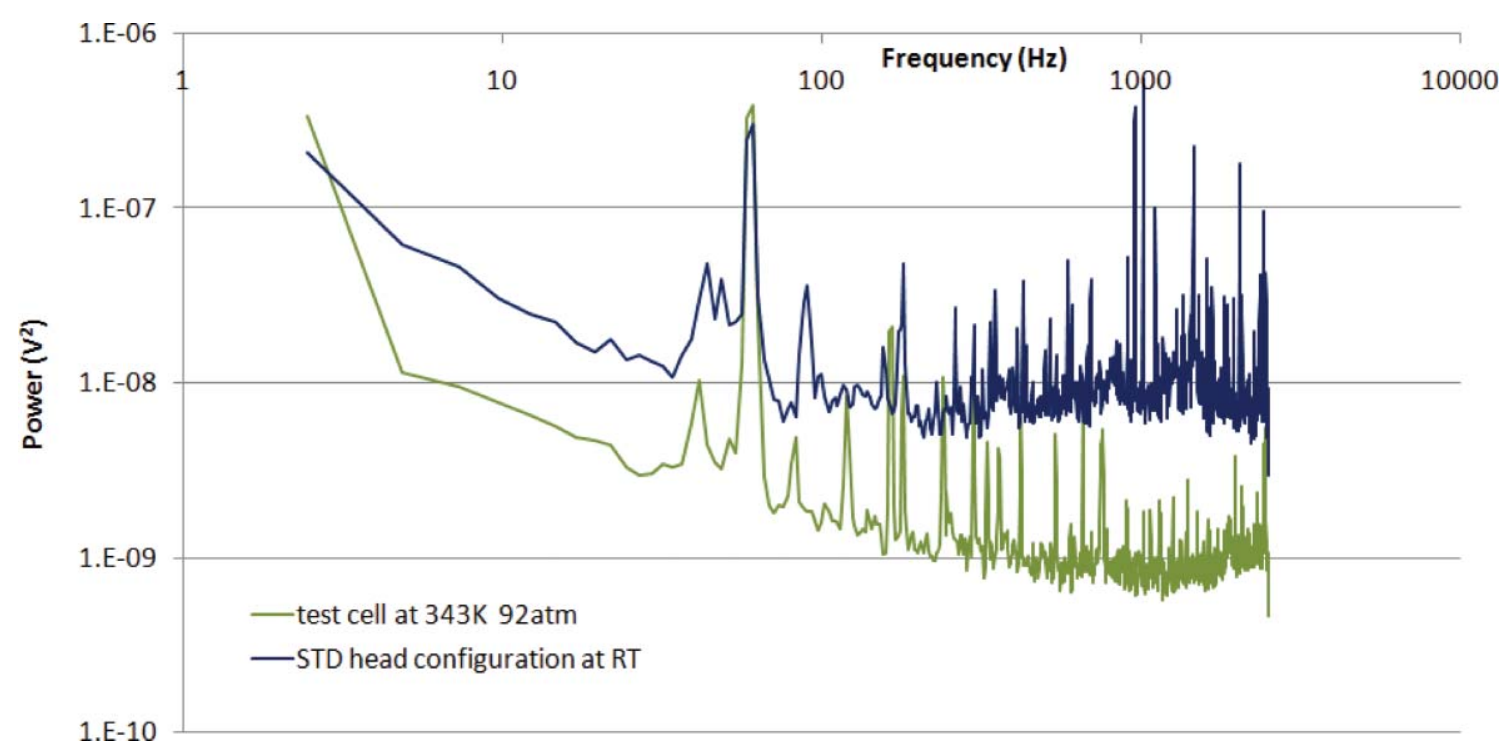

FIG. 5. (Color online) Noise comparison between a cantilever freely suspended in a Multimode AFM in its standard configuration at ambient conditions (black) and one freely suspended in the test cell filled with supercritical $\mathrm{CO}_{2}$ at $343 \mathrm{~K}$ and 92.0 atm (gray). The rms noise for the AFM in its standard configuration is calculated to be $5.9 \mathrm{mV}$ and is greater than the rms noise for the test cell, calculated to be $2.7 \mathrm{mV}$.

as pressure differences across the flexible membrane result in its rupture. Typical, pressurization rates in this study were $0.5 \mathrm{~atm} \mathrm{~min}^{-1}$.

In order to pressurize the system, all valves are initially open except for the exhaust valve (Fig. 4 valve F) at the top of the bladder accumulator. The manner in which the system is brought to pressure involves an alternating sequence, in which the bladder is first filled with $\mathrm{CO}_{2}$ up to a pressure of $\sim 3 \mathrm{~atm}$. Then, $\mathrm{N}_{2}$ is used to back-pressurize the $\mathrm{CO}_{2}$ in the bladder accumulator to a pressure of $\sim 6 \mathrm{~atm}$. This sequence is repeated until the vapor pressure of liquid $\mathrm{CO}_{2}$ is reached $(\sim 57 \mathrm{~atm})$, at which point the valve (B) between the bladder accumulator and the high-pressure syringe pump (Teledyne Isco Model 500D) is closed and the syringe pump is filled with liquid $\mathrm{CO}_{2}$ directly from the cylinder. Once the syringe pump is filled, the pressure of the entire system is slowly brought to the target pressure using the $\mathrm{N}_{2}$ cylinder and the high-pressure syringe pump initiates regulated flow within the fluid cell.

\section{RESULTS}

To determine the contribution of variations in density of the $\mathrm{scCO}_{2}$ arising from temperature and pressure fluctuations in our system, we have performed noise measurements in a stainless steel test cell, which is essentially just the fluid cell component of the high-pressure AFM head. The noise is determined using a $400 \mathrm{MHz}$ digital oscilloscope (Tektronix TDS 380) to capture the deflection signal (accessible with the Bruker AXS signal access module) resulting from reflecting the laser off a $100 \mu \mathrm{m}$ long, backside gold coated Si cantilever (K-Tek Tetra15), freely suspended in $\mathrm{scCO}_{2}$ at $343 \mathrm{~K}$ and $92 \mathrm{~atm}$. High frequency components of the deflection signal were filtered out using an RC circuit with a low-pass frequency of $(2 \pi R C)^{-1}=2002 \mathrm{~Hz}$. This setup allowed us to capture $15 \mathrm{~s}$ of data using a sampling rate of $5 \mathrm{kHz}$. We utilized the "power spectral density" procedure in IGOR PRO to obtain the frequency-dependent power spectrum and the 1-d statistical analysis function to calculate the rms noise in the signal. To compare this noise to what is present in a Multimode AFM in its standard configuration, we captured the deflection signal from a freely suspended cantilever in air at ambient temperature and pressure using the Multimode AFM head. Fig. 5 shows the power density as a function of frequency from 2.5 to $2000 \mathrm{~Hz}$. Aside from a few frequencies, the power density of the cantilever suspended in $\mathrm{scCO}_{2}$ at 343 $\mathrm{K}$ and $92 \mathrm{~atm}$ is smaller than what is measured utilizing a similar cantilever in ambient conditions using the Multimode in a standard AFM configuration across the entire bandwidth. For the test cell, the rms noise is measured to be $2.7 \mathrm{mV}$, whereas for the Multimode AFM under ambient conditions, the rms noise is measured to be $5.9 \mathrm{mV}$. And though for the test cell the detector sensitivity is unknown, making a direct comparison difficult, the deflection voltage is generated from normalization of the difference signal to the total intensity: $(\mathrm{A}-\mathrm{B}) /(\mathrm{A}+\mathrm{B})$ and so differences in light intensity reaching the photodiode are minimized. Since, in the standard configuration, one can easily discern $3.2 \AA$ monatomic steps on a freshly cleaved (1014) surface of calcite, one can reasonably conclude that noise due to density variations in the fluid has little impact on the ability to detect atomic scale steps in $\mathrm{scCO}_{2}$ using our high-pressure AFM.

The ability to image atomic scale steps on calcite at $99 \mathrm{~atm}$ and $308 \mathrm{~K}$ using our high-pressure AFM, calibrated using a $20 \mathrm{~nm}$ high, $5 \mu \mathrm{m}$ pitch standard (Ted Pella HS20MG-UM), is shown in Fig. 6(a). This image was produced in contact mode using a scan size of $5 \mu \mathrm{m} \times 5 \mu \mathrm{m}$. For comparison, we show an image of a well-defined surface of a $3 \mu \mathrm{m}$ pitch calibration grid taken at $100 \mathrm{~atm}$ and $308 \mathrm{~K}$ in Fig. 6(b). Within the one hour that we monitored this area of the calcite surface, no surface topography change could be seen during flow of anhydrous $\mathrm{scCO}_{2}$ over the surface at a rate of $500 \mu \mathrm{l} \mathrm{min}{ }^{-1}$, indicating no detectable reaction of the calcite (1014) surface, which is not unexpected. It is worth noting that the range of the piezoelectric scanner is 

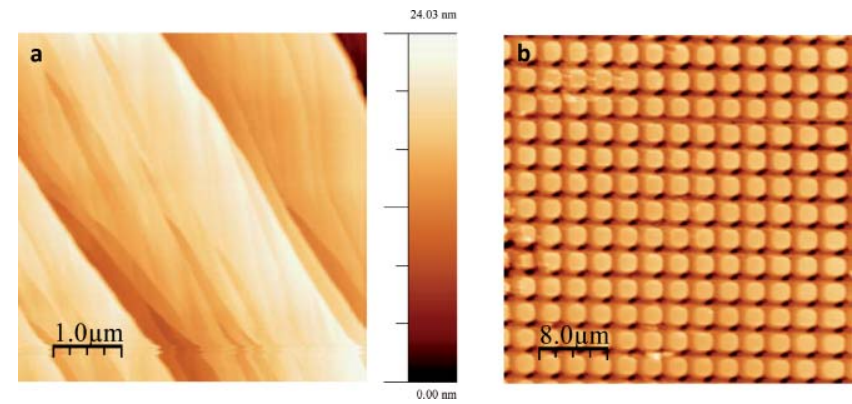

FIG. 6. (Color online) (a) A $5 \mu \mathrm{m} \times 5 \mu \mathrm{m}$ topographic image of a freshly cleaved calcite (1014) surface under dry $\mathrm{scCO}_{2}$ at $308.2 \mathrm{~K}$ and $99.3 \mathrm{~atm}$ using

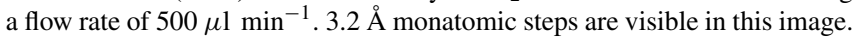
(b) A $40 \mu \mathrm{m} \times 40 \mu \mathrm{m}$ topographic image of a calibration grid with $3 \mu \mathrm{m}$ periodicity at $308.3 \mathrm{~K}$.

temperature-dependent and must be calibrated at the target operating temperature. From Hooker, ${ }^{30}$ one can estimate the temperature dependence of the transverse strain constant $\left(\mathrm{d}_{31}\right)$ for PZT-5A at $8 \times 10^{-12} \mathrm{~m} \mathrm{~V}^{-1} \mathrm{C}^{-1}$ between the temperature range of $0^{\circ} \mathrm{C}-50^{\circ} \mathrm{C}$. Given that the transverse strain constant is $-173 \times 10^{-12} \mathrm{~m} \mathrm{~V}^{-1}$ at $298 \mathrm{~K}$, a $13^{\circ}$ temperature increase (from our $295 \mathrm{~K}$ room temperature) would increase $\mathrm{d}_{31}$ by approximately $6 \%$. This change is consistent with our recalibration settings (e.g., $77.1 \mathrm{~nm} \mathrm{~V}^{-1}$ versus $72.0 \mathrm{~nm} \mathrm{~V}^{-1}$ for y sensitivity). Using a calibration grid, we have observed that pressures up to $100 \mathrm{~atm}$, however, have an insignificant effect on the scan range of these tube scanners.

Imaging of a cleaved calcite (1014) surface that has been exposed to air under ambient conditions for $20 \mathrm{~h}$ prior to placing in the high-pressure AFM shows time-dependent behavior as anhydrous $\mathrm{scCO}_{2}$ at $340 \mathrm{~K}$ and 80 atm flows across the sur-

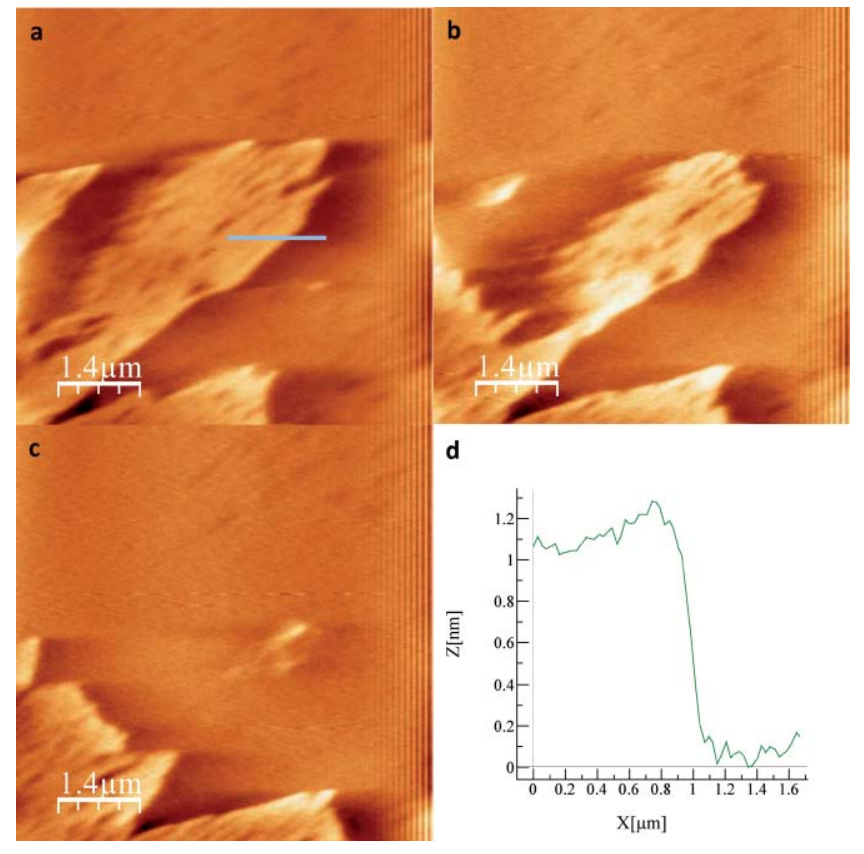

FIG. 7. (Color online) $7 \mu \mathrm{m} \times 7 \mu \mathrm{m}$ topographic images of the (1014) surface of calcite initially exposed to ambient air for $\sim 20 \mathrm{~h}$ prior to imaging under $\mathrm{scCO}_{2}$ at $308.3 \mathrm{~K}$ and $82.0 \mathrm{~atm}$ as a function of time using a flow rate of $500 \mu \mathrm{l} \mathrm{min}{ }^{-1}$. Images (a)-(c), taken 6 min apart, show dynamic processes occurring on the mineral surface. Image (d) is a cross section of a portion of image (a) (line shown) showing height of the terrace is about $1.2 \mathrm{~nm}$. face, as shown in Figs. 7(a)-7(c). From the images, it is apparent that islands approximately $1.2 \mathrm{~nm}$ high (Fig. 7(d)) are disappearing from the calcite surface as a result of this flow. This dynamic process that is occurring on the surface is likely due to changes in surface chemistry that have occurred during the induction period between cleavage and imaging. Kendall and Martin $^{31}$ have shown using polarization force microscopy that a $1.5 \mathrm{~nm}$ high film forms on the surface of calcite under humid conditions which they attribute to the formation of a hydrated calcium carbonate phase that is stabilized by the underlying calcite surface. It is not unreasonable to expect that flowing anhydrous $\mathrm{scCO}_{2}$ over the surface of such a film would dehydrate the loosely bound water in this phase and result in the decomposition of this overlayer phase. In that respect our observations are consistent with those of Kendall and Martin.

\section{CONCLUSIONS}

We have successfully designed, constructed, and demonstrated a functioning high-pressure AFM that is capable of in situ imaging of monatomic steps on mineral surfaces in supercritical $\mathrm{CO}_{2}$ at pressures up to $100 \mathrm{~atm}$ and temperatures up to $\sim 350 \mathrm{~K}$. Images of freshly cleaved and aged calcite (1014) surfaces under $\mathrm{scCO}_{2}$ flow show both atomic resolution and the observations of real-time in situ processes. While calcite represents a good model system to demonstrate highpressure AFM functionality, it is our intention to use the apparatus to investigate the metal carbonation of silicate minerals in $\mathrm{scCO}_{2}$ to help understand fundamental reactions that occur during processes relevant to carbon sequestration. And while our focus is primarily on geochemical processes, this apparatus is also suitable for study of other gaseous or aqueous hyperbaric solid-fluid chemical processes at moderate temperatures.

\section{ACKNOWLEDGMENTS}

This research was supported by the Carbon Sequestration Laboratory Directed Research and Development (LDRD) Initiative at Pacific Northwest National Laboratory (PNNL). The research was performed using the Environmental Molecular Sciences Laboratory (EMSL), a national scientific user facility sponsored by the (U.S.) Department of Energy's (DOE) Office of Biological and Environmental Research and located at PNNL.

${ }^{1}$ R. S. Arvidson, M. Collier, K. J. Davis, M. D. Vinson, J. E. Amonette, and A. Luttge, Geochim. Cosmochim. Acta 70, 583 (2006).

${ }^{2}$ J. Bisschop, D. K. Dysthe, C. V. Putnis, and B. Jamtveit, Geochim. Cosmochim. Acta 70, 1728 (2006).

${ }^{3}$ P. M. Dove and F. M. Platt, Chem. Geol. 127, 331 (1996).

${ }^{4}$ G. Jordan and W. Rammensee, Geochim. Cosmochim. Acta 62, 941 (1998).

${ }^{5}$ A. S. Lea, J. E. Amonette, D. R. Baer, Y. Liang, and N. G. Colton, Geochim. Cosmochim. Acta 65, 369 (2001).

${ }^{6}$ A. S. Lea, T. T. Hurt, A. El-Azab, J. E. Amonette, and D. R. Baer, Surf. Sci. 524, 63 (2003).

${ }^{7}$ Y. Liang, A. S. Lea, D. R. Baer, and M. H. Engelhard, Surf. Sci. 351, 172 (1996).

${ }^{8}$ S. L. S. Stipp, C. M. Eggleston, and B. S. Nielsen, Geochim. Cosmochim. Acta 58, 2023 (1994).

${ }^{9}$ H. H. Teng, Geochim. Cosmochim. Acta 68, 253 (2004). 
${ }^{10} \mathrm{M} . \mathrm{Xu}, \mathrm{X} . \mathrm{Hu}, \mathrm{K} . \mathrm{G}$. Knauss, and S. R. Higgins, Geochim. Cosmochim. Acta 74, 4285 (2010).

${ }^{11}$ A. J. Gratz, S. Manne, and P. K. Hansma, Science 251, 1343 (1991).

${ }^{12}$ S. V. Yanina, K. M. Rosso, and P. Meakin, Geochim. Cosmochim. Acta 70, 1113 (2006)

${ }^{13}$ G. Jordan, S. R. Higgins, and C. M. Eggleston, American Mineralogist 84, 144 (1999).

${ }^{14}$ S. R. Higgins and X. Hu, Geochim. Cosmochim. Acta 69, 2085 (2005).

${ }^{15}$ S. R. Higgins, C. M. Eggleston, K. G. Knauss, and C. O. Boro, Rev. Sci. Instrum. 69, 2994 (1998).

${ }^{16} \mathrm{~S}$. R. Higgins, G. Jordan, and C. M. Eggleston, Geochim. Cosmochim. Acta 66, 3201 (2002)

${ }^{17}$ G. Jordan, S. R. Higgins, C. M. Eggleston, K. G. Knauss, and W. W. Schmael, Geochim. Cosmochim. Acta 65, 4257 (2001).

${ }^{18}$ G. D. Saldi, G. Jordan, J. Schott, and E. H. Oelkers, Geochim. Cosmochim. Acta 73, 5646 (2009).

${ }^{19}$ S. R. Higgins, D. Bosbach, C. M. Eggleston, and K. G. Knauss, J. Phys. Chem. B 104, 6978 (2002).
${ }^{20}$ G. Jordan, S. R. Higgins, C. M. Eggleston, S. M. Swapp, D. M. Janney, and K. G. Knauss, Geochim. Cosmochim. Acta 63, 3183 (1999).

${ }^{21}$ K. Aldushin, G. Jordan, and W. W. Schmahl, Geochim. Cosmochim. Acta 70, 4380 (2006).

${ }^{22}$ H. Shao, J. R. Ray, and Y.-S. Jun, Environ. Sci. Technol. 44, 5999 (2010).

${ }^{23}$ M. Sorai, T. Ohsumi, and M. Ishikawa, Energy 30, 2334 (2005).

${ }^{24}$ G. Jordan and J. M. Astilleros, Am. Mineral. 91, 619 (2006).

${ }^{25}$ R. Span and W. Wagner, J. Phys. Chem. Ref. Data 25, 1509 (1996).

${ }^{26}$ H. Tang, E. Gulari, and E. W. Rothe, J Supercrit. Fluids 18, 193 (2000).

${ }^{27}$ W. J. Tropf and M. E. Thomas, in Handbook of Optical Constants of Solids III, edited by E. D. Palik (Academic, San Diego, 1998), p. 651.

${ }^{28}$ W. L. Bourcier and H. L. Barnes, in Hydrothermal Experimental Methods, Edited by G. C. Ulmer and H. L. Barnes (Wiley, New York, 1987), p. 189.

${ }^{29}$ W. E. Seyfried, D. R. Janecky, and M. E. Berndt, in Hydrothermal Experimental Methods, edited by G. C. Ulmer and H. L. Barnes (Wiley, New York, 1987).

${ }^{30}$ M. W. Hooker, NASA/CR-1998-208708, (1998).

${ }^{31}$ T. A. Kendall and S. A. Martin, J. Phys. Chem. A 111, 505 (2007). 


\section{DISCLAIMER}

This document was prepared as an account of work sponsored by the United States Government. While this document is believed to contain correct information, neither the United States Government nor any agency thereof, nor The Regents of the University of California, nor any of their employees, makes any warranty, express or implied, or assumes any legal responsibility for the accuracy, completeness, or usefulness of any information, apparatus, product, or process disclosed, or represents that its use would not infringe privately owned rights. Reference herein to any specific commercial product, process, or service by its trade name, trademark, manufacturer, or otherwise, does not necessarily constitute or imply its endorsement, recommendation, or favoring by the United States Government or any agency thereof, or The Regents of the University of California. The views and opinions of authors expressed herein do not necessarily state or reflect those of the United States Government or any agency thereof or The Regents of the University of California.

Ernest Orlando Lawrence Berkeley National Laboratory is an equal opportunity employer. 